individuals and organisations from across society to confront the growing issue of obesity. This movement promotes and supports the adoption of healthy behaviours through a vast array of channels and networks, helping people to change and to live a healthier lifestyle.

Method: In developing the campaign, the Department of Health in England was advised by leading academics working in nutrition, child psychology and physical activity, and undertook a major programme of quantitative, qualitative and ethnographic research. Armed with these insights and a detailed audience segmentation the Department worked with M\&C Saatchi to develop a communications strategy and create a brand with which to build a movement for change. The objective was to create a societal movement that would engage families, communities, grass roots organisations, teachers' healthcare professionals, NGOs and businesses, so that everyone could play their part in combating obesity. To create and then grow these movement some strategy principles were developed and deployed.

One: Make change positive. Rather than shouting at people Change4Life was created to be positive and supportive. This manifested itself in the name, colours and assets of the brand.
Two: Overcome the powerful rejection of obesity messages by reframing the problem as a societal one, rather than it being 'your fault'.

Three: Shifting the focus from 'fat bodies' to 'fat in the body' in order to avoid people excluding themselves and their families on physical grounds.

Four: Land the severity of the issue by revealing the true health harms caused by excess levels of body fat.

Five: Personalise the issue by finding levers that made the message relevant to people and their families.

Results: Over 400000 families have joined Change4Life. Change4Life has built over 200 national partnerships; $44 \%$ of community venues have displayed Change4Life materials; 26000 local supporters have held over a million conversations with the public about healthy lifestyles and National Health Service staff has ordered over six million items of Change4Life collateral. A third of all parents claim to have taken action as a direct result of Change4Life communications.

Conclusions: The programme has showed encouraging results in its first year. The team is working to underpin claimed data with proven measures of behaviour change, including an academic study and analysis of purchasing data from a major supermarket.

\title{
New instruments for communication: web, mobiles, sms, social networks
}

\author{
Jaqueline Harding
}

\section{Director of Tomorrow's Child and www.Parentchannel.tv}

The communication landscape is changing: Why do humans constantly desire new ways to communicate? Now that multi-modal texts are demanding that we rethink what it means to be literate it is important that we question how the reader/viewer's expectations have evolved and how new instruments for communication are being embraced. There is a growing demand for bite-sized information: it appears that, as consumers of communication, we are constantly seeking out faster methods of communication. Humans are distinct from other mammals. We are responsive to human interaction; biologically wired to connect with an altruistic drive to cooperate. Interestingly, it is recognised that socially connected people are less prone to stress. Perhaps there is a survival imperative that drives this demand for communication?

Traditional methods of communicating messages about nutrition and exercise are ceasing to work. Current discourse tends to concern access to information and new types of information. The rise of Internet TV is powerful: it is on the move; it is mobile; when you want it; where you want it; how you want it. So, how can new tools of communication help to present positive 'health' messages?

Addressing the target audience. Parents: Parents are children's first carers and promoters of their health. We sought to develop a more dynamic media-based approach to developing health awareness for both parent and child. Tomorrow's Child is founded on the North American Indian principle: no decision ever to be made without considering the needs of children seven generations hence. www. parentchannel.tv is a successful UK government initiative to bring key messages to parents of 5-19 years around: learning, well-being and behaviour. Tomorrow's Child is the production company who are providing short engaging and empowering films for this free online service. For example, films regarding:

How to get your children to enjoy eating healthy food; How to get a balanced diet on the table and Understanding and feeding your young vegetarian. Attracting the audience and effective methods of communication: Through online strategies such as, blogs, facebook, tweeting, vidtweets, youtube and most particularly through syndication methods, 